\title{
Desenvolvimento de revistas científicas em mídia digital - o caso da Revista Produção Online
}

\author{
Cláudia Regina Ziliotto Bomfá \\ Professora do SAD/CTC/EPS/UFSC \\ E-mail: claudia@deps.ufsc.br
}

\section{João Ernesto E. Castro}

Editor da revista científica eletrônica Produção On-line. Professor do CTC/EPS/UFSC.

E-mail: castro@deps.ufsc.br

\section{Resumo}

O artigo descreve a elaboração do primeiro periódico científico, em mídia digital, da área de engenharia de produção - a revista científica Produção Online, do Curso de Pós-graduação da Universidade Federal de Santa Catarina. Explicitam-se as ações desenvolvidas para sua manutenção, como instrumento de comunicação científica em suporte digital. Relata-se todo o processo de produção científica, desde o recebimento do artigo até sua publicação eletrônica. Chama-se a atenção para a proposta de oferecer à comunidade científica uma revista eletrônica, com baixos custos em relação à publicação em meio impresso, possibilitando a divulgação das pesquisas científicas em tempo real, e ao mesmo tempo oferecer mecanismos eletrônicos que agilizem o processo de submissão, avaliação e leitura dos artigos, facilitando a rápida circulação do conhecimento científico.

\section{Palavras-chave}

Elaboração de periódico científico eletrônico; Tecnologia da informação; Comunicação científica.

\section{Development of scientific journals in digital media - the case of Produção Online Journal}

\begin{abstract}
This article describes the creation of the very first scientific electronic journal of Industrial Engineering in Brazil, making explicit all the actions that were taken to keep this journal working as an alternative for publishing scientific material on the web. The Journal Produção Online is put out by the Production Engineering Department of Santa Catarina's Federal University. This article also draws attention to the fact that publishing through this media has lower costs than printed journals, as well as making scientific publication faster. The electronic tools that have been used in this experience help to select articles to be published and are also a way of making it easier for researchers to read and submit articles to this journal as well as improving scientific communication.
\end{abstract}

\section{Keywords}

Scientific journal; Electronic media; Information technology.

\section{INTRODUÇÃO}

O conhecimento científico e tecnológico tem sido duplicado a cada 10 anos. O "ir e vir" de um artigo para os revisores de uma revista cientifica é uma das causas apontadas para a lentidão na divulgação das pesquisas nacionais e internacionais (em média dois anos para ser publicado). Outro fato é a falta de um modelo de gestão e acompanhamento das fases de uma revista. Os responsáveis por revistas impressas têm de conviver com problemas de altos custos de publicação e distribuição e falta de investimentos, obrigando a redução dos números de exemplares publicados que, na sua maioria, são semestrais. A informática associada às telecomunicações tornou possível transportar, economicamente, enormes quantidades de informações, publicando dados em tempo real. As distâncias e as fronteiras nacionais e internacionais deixaram de ser barreiras nestas relações. Esta iniciativa reconhece a importância da pesquisa nos cenários nacional e mundial. Muller (2000, p.76) explica que há muitos problemas com o modelo tradicional de periódico científico, estes vêm se agravando à medida que se desenvolve a tecnologia e se modifica a expectativa sobre os meios de comunicação científica. A autora destaca os principais problemas mencionados pelos pesquisadores:

- um artigo submetido a uma revista científica demora a passar pela análise do corpo editorial, o que acaba atrasando, muitas vezes, por um ano sua publicação;

- o custo para adquirir os volumes das revistas é alto e manter atualizada a coleção também custa caro;

- os formatos impressos caracterizam-se por apresentar a informação de forma rígida e estática;

- inacessibilidade em encontrar artigos com assuntos de interesse, devido à grande demanda de periódicos e poucas ferramentas que permitem a procura destes artigos;

- dificuldades em encontrar determinados artigos, mesmo porque nem sempre as bibliotecas possuem todos os periódicos que são publicados.

Outro fator relevante diz respeito às determinações dos órgãos de pesquisa, que exigem dos pesquisadores a 
produção científica em periódicos indexados. Um estudo desenvolvido por Bomfá (2003) apresenta o quadro atual da qualidade dos principais periódicos científicos impressos da área de engenharia de produção, com base nos critérios de qualidade ditados pelas bases de dados internacionais. Os resultados possibilitam identificar as seguintes problemáticas:

- os periódicos analisados não apresentam, de forma clara e organizada, seus elementos constitutivos. Muitas informações são omitidas, ou muitas vezes deixam de apresentar uniformidade, prejudicando a qualidade do periódico;

- ausência de normas específicas para a apresentação dos artigos e elaboração das referências bibliográficas;

- baixa penetração dos periódicos em outros estados nacionais;

- alto índice de autores e avaliadores vinculados à instituição de origem dos periódicos;

- atrasos na avaliação e publicação dos artigos;

- falta, principalmente, de um modelo de gestão e acompanhamento da produção de artigos científicos.

Todo este descontentamento em relação às revistas científicas coloca em evidência a possibilidade de se repensar o periódico impresso. $O$ periódico científico eletrônico surge como alternativa para amenizar as dificuldades mencionadas. Não se trata de substituir o periódico impresso, mas propor um suporte que certamente terá espaço junto às publicações convencionais.

A proposta de oferecer à comunidade científica da área de engenharia de produção uma revista científica eletrônica dá-se pelos altos custos exigidos na publicação em meio impresso, oferecendo um diferencial, disseminando e possibilitando a divulgação das pesquisas científicas em tempo real.

Acrescentando a isto a implementação de uma ferramenta que possibilite a gerência e acompanhamento dos textos enviados junto aos colaboradores do corpo editorial da revista. Esse suporte eletrônico permitirá popularizar a pesquisa científica ao usuário, agregando facilidades ao público em geral. O suporte em mídia eletrônica permitirá a constante proliferação de artigos, propondo conteúdo versátil e rapidez na resposta aos autores.

\section{BREVE HISTÓRICO DA COMUNICAÇÃO CIENTÍFICA EM MÍDIA DIGITAL}

A comunicação científica em mídia digital está sendo amplamente discutida com o rápido desenvolvimento da Internet, que desde 1994 vem modificando o acesso à informação. As discussões giram em torno de propostas que visam a passar de um sistema de comunicação científica impressa tradicional para um sistema eletrônico.

Levacov (1997) afirma, baseado em Barret (1989), Ogden (1992) e Adams (1993), "que o avanço da tecnologia nos coloca à frente de uma revolução, comparada à invenção dos tipos móveis por Gutenberg”.

A passagem do suporte impresso para o eletrônico modificará a maneira de acessar, ler e assimilar as informações. Para refletir sobre a comunicação científica na Internet, torna-se fundamental que se reporte ao início do uso do computador como disseminador da informação entre pesquisadores.

Aguiar (1997) explica que em 1969 anunciou-se o primeiro projeto de rede de computadores, utilizando novas tecnologias, a Advanced Research Projects Agency (ArpaNet), criada pelo Departamento de Defesa do governo dos EUA. Esse projeto permitiu que se pudesse conectar, pela primeira vez, quatro universidades americanas - Stanford Research Institute, UCLA, UC Santa Bárbara e a Universidade de Utah -, além dos centros de pesquisa militar. Em 1970, no auge do sucesso da ArpaNet, pesquisadores e alunos de universidades norte-americanas já podiam desfrutar os recursos de e-mail. Aos poucos, os recursos, até então destinados ao uso militar, incorporaram-se a outros tipos de serviços de comunicação a distância, tornando-se disponíveis a todos.

Na década de 70, a rede foi utilizada amplamente com fins científicos e acadêmicos. De acordo com Stumpf (1996), com o avanço da tecnologia, a editoração eletrônica possibilitou a qualidade e a agilidade na produção de revistas. A autora afirma que "(...) entre as tentativas de informatizar todo o processo editorial, as mais significativas apresentadas pela literatura são dos projetos EPC, desenvolvidos nos Estados Unidos, e BLEND, na Inglaterra”.

O conceito de EPC - Centros de Processamento Editorial - iniciou nos anos 70, sob o patrocínio da National Science Foundation. Constituiu-se em um empreendimento cooperativo entre publicadores, com a finalidade de oferecer suporte automatizado para todas 
as etapas envolvidas na produção das revistas, visando ao barateamento dos custos. Essas etapas vão desde a submissão do trabalho pelo autor e a avaliação pelos pares, até a editoração, impressão e administração da revista. As dificuldades encontradas para a viabilização desses centros foram referentes à compatibilização dos equipamentos e processamentos de texto dos autores e dos árbitros (referees). Hoje, grande parte desses problemas já se encontra solucionada e quase todas as revistas americanas encontram-se totalmente automatizadas (Stumpf, 1996).

$\mathrm{O}$ projeto Birngham and Loughborough Electronic Network Development (Blend) foi desenvolvido, na década de 80 , pelas universidades dessas duas cidades, na tentativa de avançar um pouco mais na produção das revistas. Além de automatizar todas as etapas do processo, o projeto, financiado pela Britsh Library, constitui-se em uma alternativa de substituição total da publicação impressa pela armazenagem eletrônica dos artigos e, conseqüentemente, seu acesso.

As dificuldades encontradas para a viabilização do programa foram referentes, também, à compatibilização dos equipamentos e programas, apresentando ainda como limitação os altos custos envolvidos. Como não obteve aceitação total dos participantes, a avaliação final conclui que as revistas em papel ainda iriam perdurar por algum tempo (Stumpf, 1996)

Em 1978, é lançado o primeiro sistema de troca de mensagens, possibilitando que usuários individuais se comuniquem via modem. A Usenet-1979, cujo objetivo de distribuir informações ao usuário do sistema Unix, torna-se o mais abrangente e popular provedor mundial de conferências eletrônicas e grupos de discussão.

A década de 80 marca a propagação da ArpaNet, visto que já não estava sob o poder do uso militarista. $\mathrm{O}$ programa Transmission Control Protocol (TCT), responsável por reorganizar a informação e o Internet Protocol (IP), por endereçar e transmitir os dados, interligam computadores em rede, permitindo a comunicação em rede.

Em 1989, com o advento da WWW (Word Wide Web), os jornais e as revistas começaram a adaptar-se ao suporte on-line. A linguagem do hipertexto surge para simplificar o acesso às informações, que até então somente eram visíveis mediante uma série de comandos digitados na tela. Em 1991, abre-se a primeira conexão do Brasil com a Internet, por meio da Fapesp. A Fundação Nacional de Ciências dos EUA libera a Internet para uso comercial.
Em 1993, as publicações tornam-se visíveis em meio digital, trazendo novas perspectivas e projetos de uso on-line. Neste contexto, surgem propostas de oferecer periódicos científicos eletrônicos, com o intuito de facilitar o acesso e a divulgação da pesquisa, permitir a recuperação da informação de modo ágil, oferecer largo alcance, diminuir os custos com impressão e postagem, oferecendo fluxo contínuo de artigos científicos.

A seguir, descreve-se a experiência obtida na elaboração e implantação da revista científica eletrônica de engenharia de produção Produção Online, bem como os resultados obtidos ao longo de dois anos de publicação.

\section{O CASO DA REVISTA PRODUÇÃO ONLINE}

A Revista Produção Online é um periódico científico eletrônico da área de engenharia de produção, de acesso gratuito e sem versão impressa, destinado basicamente a publicações de trabalhos científicos, elaborados por alunos dos cursos de pós-graduação, ou trabalhos de professores e pesquisadores da área de engenharia de produção e correlatas. Surgiu da parceria entre a Associação Brasileira de Engenharia de Produção (Abepro) e o Laboratório de Sistemas de Apoio à Decisão (LabSad) do Departamento de Engenharia de Produção, da Universidade Federal de Santa Catarina, com o intuito de estimular a produção de trabalhos científicos, contribuindo para o desenvolvimento contínuo da ciência. O objetivo principal é incentivar os pesquisadores da área, facilitando o processo de publicação de artigos científicos, técnicos, estudos de caso, artigos de revisão, dentre outros trabalhos.

O projeto tem por objetivos específicos:

- eliminar os custos com papel, impressão e postagem;

- promover a realização de pesquisa e produção de conhecimento entre pesquisadores da área;

- oferecer suporte em mídia digital, facilitando a inserção de artigos e, conseqüentemente, ampliando a disseminação dos trabalhos científicos;

- estimular o desenvolvimento do rigor científico, oferecendo ao pesquisador a possibilidade de ter seu trabalho avaliado por seus pares na sua área de atuação;

- contribuir para a qualidade da ciência nacional, buscando a indexação em bases internacionais. 


\section{Cláudia Regina Ziliotto Bomfá / João Ernesto E. Castro}

\section{Histórico}

Em janeiro de 2001, a diretoria da Associação Brasileira de Engenharia de Produção (Abepro) e seus membros manifestaram o desejo de oferecer uma nova publicação, em mídia digital, direcionada a pesquisadores e profissionais da área engenharia de produção e áreas correlatas. A iniciativa veio em resposta às necessidades de reduzir custos com papel e impressão do fascículo, postagem e distribuição, bem como de agilização do processo de recebimento, avaliação e publicação de artigos. Além disso, visou-se a oferecer à comunidade científica uma revista eletrônica elaborada de acordo com os critérios de indexação das bases de dados internacionais.

Em julho de 2001, propôs-se a criação de uma revista que suprisse essa lacuna, e então os membros da Abepro foram convidados a opinar e ajudar a definir o periódico. A princípio foram apresentadas diversas idéias a respeito do leiaute, das normas para publicação, da viabilização dos artigos, da composição do corpo de referees, do gerenciamento do processo de produção científica, entre outros aspectos relevantes. Em agosto de 2001, foram nomeados os membros do conselho editorial da revista.

Em outubro de 2001, foi lançado o primeiro número da revista, no XXI Encontro Nacional de Engenharia de Produção (Enegep), realizado em Salvador. O lançamento tinha por objetivo divulgar a Revista Produção Online em um evento de cunho internacional, aproveitando a grande leva de profissionais advindos de diversos estados brasileiros. $\mathrm{O}$ evento possibilitou vincular a revista à editora Abepro, e ainda contatar com professores de diversas instituições para então formalizar o corpo de referees. No primeiro mês de sua publicação, a revista já contava com 326 visitantes.

O segundo número, lançado em fevereiro de 2002, além de publicar os artigos, ofereceu um espaço para resumos de teses e dissertações e ainda um link para a página do Programa de Pós-graduação em Engenharia de Produção da Universidade Federal de Santa Catarina, com os resumos de teses e dissertações. Foram inseridas também as normas para referenciar documentos eletrônicos e orientações que se destinam à normalização de artigos a serem publicados em revistas técnicas e científicas, em obediência à Associação Brasileira de Normas Técnicas.

O terceiro volume, lançado em outubro de 2002, obteve a adesão de colaboradores internacionais, sendo três de Portugal e um do Canadá, certamente um passo fundamental para a aceitação do periódico em bases internacionais.

\section{Intenção do projeto}

A comunidade científica da área de engenharia de produção já contava com algumas revistas impressas para a publicação de artigos científicos. Porém, sentia-se a falta de um veículo de publicação em mídia digital capaz de atender às exigências do público de pesquisadores, que destaca como pontos negativos:

- insatisfação em relação à morosidade na avaliação dos artigos;

- atraso na periodicidade dos números das publicações;

- pouca abrangência da revista impressa;

- falta de números impressos em bibliotecas nacionais;

- falta de uma revista em mídia digital, nacional com indexação em bases internacionais.

\section{Benefícios Esperados}

A criação da revista busca trazer vários benefícios à comunidade científica, com potencial para reverter o quadro descrito acima. Citam-se, entre outros:

- os pesquisadores terão acesso a uma revista nacional em mídia digital, na língua portuguesa, de nível internacional;

- a comunidade científica da área de engenharia de produção poderá contar com acesso gratuito à revista, seja para submeter os artigos ou para ler os números publicados;

- além do acesso livre, pode-se ressaltar a abrangência oferecida pelo suporte on-line, visto que qualquer pessoa de qualquer lugar poderá beneficiar-se dos serviços;

- os autores poderão publicar os artigos em uma revista indexada, sendo esta uma exigência da Capes;

- será possível ainda agilizar o processo de recebimento, envio para avaliadores e publicação dos artigos.

\section{Propostas iniciais para a concepção da revista}

A principio, determinou-se que os artigos fossem redigidos em português, não descartando-se a possibilidade de, futuramente, solicitar ao autor uma segunda versão em inglês.

A publicação dos artigos seria somente em meio eletrônico, sendo posteriormente armazenados os números anteriores em CD-ROOM, objetivando-se a recuperação da informação. 
A revista somente receberia artigos advindos de pósgraduandos, pesquisadores e professores. Determinou-se o acesso público e gratuito, com possibilidades de avaliações futuras a respeito. Estipulou-se periodicidade quadrimestral para os cinco primeiros números, sendo alterada para trimestral com o aumento do recebimento de artigos.

\section{Processo de produção científica da Revista Produção Online}

Entende-se que uma revista científica produzida em mídia digital deve apresentar-se diferentemente de uma revista científica em mídia impressa.

McAdams (1995) explica que não há relação alguma entre o papel e a tela do computador, e afirma que "o texto em uma tela não é jornal, não é revista, não é um livro”.

Os jornais e revistas on-line concentram características de outras mídias - rádio, tevê, vídeo, multimídia -, para tanto, são precursores de um novo veículo comunicativo, que tem como ponto principal a informação em rede. A produção e distribuição em rede representa uma revolução sobre a mídia impressa, visto que as notícias podem correr nos quatro cantos do planeta em questão de segundos, podendo ainda ser atualizadas instantaneamente, o que não acontece com o texto impresso (Manta, 1997).

A princípio, baseando-se na assertiva de Manta, a simples transposição de uma mídia impressa para o ambiente digital não é suficiente para se obter um periódico de qualidade. $\mathrm{O}$ autor destaca diversas vantagens da revista eletrônica em relação à impressa, o que se descreve a seguir: a edição on-line deve sempre superar a versão impressa, trazendo à tona informações e dados que se encontram ausentes no periódico impresso; por tratarse de um suporte digital, tem-se maior acesso a informações paralelas, por meio de links que possibilitam ao internauta navegar e acessar outros elementos multimídia (sites, imagens, portais, vídeo, som, entre outros); o leitor tem a possibilidade de recorrer ao banco de dados e rever as edições anteriores do periódico; acessar fóruns de discussão e chat com a presença de personalidades, participando de entrevistas e conversas no instante exato em que se está conectado; a possibilidade de se fazerem listas de discussão com assuntos específicos do periódico, ao qual está se propondo; acesso a links direcionados para ferramentas de busca, que podem auxiliar no momento em que se quer consultar para tirar dúvidas, ou complementar o assunto com outras fontes de pesquisa, outros sites, portais com assuntos específicos; atualização freqüente das notícias, o que realmente virtualiza a informação, tornando-a inédita a cada segundo; a digitalização da informação faz da mídia on-line um veículo comunicacional de rápido acesso, com notícias atualizadas instantaneamente, e, a cada segundo, o que é impossível de se fazer na mídia impressa; enquanto tem-se na edição impressa limites para a produção de textos, no periódico eletrônico tem-se o livre acesso; enquanto há na edição impressa restrições e limitações de espaço, para a produção de um texto, no periódico eletrônico presencia-se o livre acesso à informação, quando o mesmo texto pode trazer consigo links e hipertextos. O autor complementa enfatizando a importância de construir um site muito bem organizado, de modo a facilitar a consulta e o acesso imediato às informações, sendo esses fatores relevantes para a aceitação do periódico.

Vale a pena lembrar que produzir uma edição eletrônica exige critérios que se adaptem ao suporte digital. É o que será discutido a seguir. Na verdade, o suporte digital permite oferecer, ao leitor de revistas científicas, mecanismos eletrônicos que agilizem o processo de submissão, avaliação e leitura dos artigos, facilitando a rápida circulação do conhecimento científico. Pode-se traçar as etapas do processo de produção de uma revista científica eletrônica, desde o recebimento de um artigo até sua publicação em mídia digital.

Submissão dos artigos

A figura 1 apresenta as fases do processo de gerenciamento da Revista Científica Eletrônica Produção Online.

A primeira etapa consiste no recebimento do artigo, enviado pelo autor. A Revista Produção Online aceita submissão de artigos em fluxo contínuo, ou seja, um artigo pode ser enviado a qualquer momento, sendo que, após sua aprovação, o mesmo será divulgado na edição seguinte. Ao acessar o endereço eletrônico, o autor deve ler atentamente as instruções a respeito da elaboração dos artigos. Os trabalhos científicos submetidos à edição

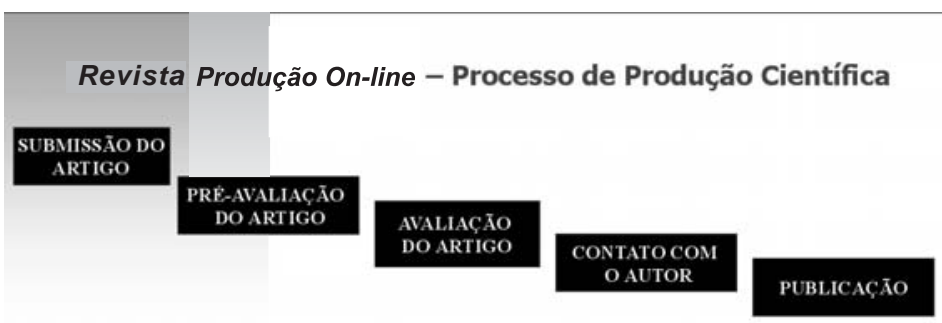

Fonte: Bomfá, 2003. 


\section{Cláudia Regina Ziliotto Bomfá / João Ernesto E. Castro}

deverão atender a todas as exigências estipuladas, para que possam ser encaminhados aos avaliadores.

Determina-se que os artigos sejam originais, destinados exclusivamente para a revista, ou seja, não terem sido publicados em nenhum outro evento (congressos, simpósios e seminários), revista ou periódico. As submissões são enviadas somente via e-mail, sendo que, ao ser recebido pela revista, o artigo é registrado mediante um número de protocolo, antes mesmo de ser submetido à avaliação. A primeira versão do artigo é enviada no formato Word, sendo a versão final, para publicação, enviada no formato PDF. Essa exigência se dá pela necessidade de omitir todas as informações que identifiquem os autores, no momento em que se envia o artigo para o corpo avaliativo.

Normalmente o artigo é submetido três vezes pelo autor, sendo a primeira versão encaminhada ao corpo de referees; a segunda versão revisada pelo autor, mediante sugestão dos avaliadores; a terceira e última versão para publicação.

Todo o processo de avaliação, desde o recebimento do artigo até a sua publicação, demora em média quatro meses, dependendo muitas vezes da colaboração do próprio autor, que deve acatar as alterações sugeridas pelo corpo de referees.

Após enviar um artigo para avaliação o autor recebe automaticamente um comprovante de envio do artigo, o qual poderá ser impresso para seu próprio controle.

Seleção dos referees

A segunda etapa consiste na seleção dos referees, que no caso da Revista Produção Online, são dois avaliadores. Geralmente é feita uma pré-avaliação, juntamente com o editor, para posteriormente serem escolhidos os consultores que se relacionam com o tema do trabalho. Na falta de referees para determinada área de artigo, seleciona-se um referee ad hoc, da própria instituição, para contribuir com a avaliação. As estatísticas dos artigos encaminhados por área podem ser observadas no quadro 1 .

Segundo Garcia et alii (2000), “os árbitros não abandonam tendências e valores subjetivos, e acabam por privilegiar correntes teóricas, países, instituições e indivíduos que detêm naquele momento a autoridade na ciência” Nesse sentido, torna-se imprescindível manter sigilo a respeito da identificação do nome, instituição e estado dos autores. Para tanto, envia-se para o avaliador somente o conteúdo do artigo, via e-mail, juntamente com a ficha de avaliação e as normas de apresentação.
QUADRO 1

Número de artigos por área da engenharia de produção

Número de artigos recebidos por área

Gerência de Produção - 13,13\%

Qualidade - 14,28\%

Gestão Econômica - 7,6\%

Ergonomia e Segurança do Trabalho - 11,40\%

Engenharia do Produto - 8,57\%

Pesquisa Operacional - 5,71\%

Estratégia e Organizações - 15,24\%

Gestão da Tecnologia - 5,71\%

Sistemas de Informação - 6,66\%

Gestão Ambiental - 9,52\%

Ensino de Engenharia de Produção - 1,9\%

Avaliação dos artigos

A terceira etapa consiste na avaliação do artigo propriamente dita, realizada pelos pares. Considerado requisito fundamental para o avanço da pesquisa científica em nossos dias, a revisão por pares é o indicador de qualidade aceitável no meio científico, por ser responsável pela propagação rápida da informação.

Quando surgem na Europa as primeiras revistas científicas - Journal des Sçavants, na França, e Philosophical Transactions, na Inglaterra -, coloca-se à tona o sistema de avaliação da produção científica pelos membros da comunidade conhecido como peer review (revisão por pares) ou referee system (sistema de arbitragem). No Brasil, usam-se geralmente várias traduções para o termo referee, como árbitro, avaliador, parecista e revisor.

Segundo Pessanha (1998), o início oficial do processo de arbitragem deu-se apenas em 1753, quando a Royal Society of London passa a responsabilizar-se formalmente pela avaliação dos textos publicados. Com o crescimento da demanda de artigos científicos para publicação, surge a preocupação, por parte da comunidade científica, com a qualidade dos trabalhos publicados. Nesse sentido, definem-se os papéis do editor científico da revista e dos avaliadores, que devem desempenhar juntos a avaliação dos trabalhos. O caráter científico é atribuído ao periódico de acordo com o padrão de qualidade editorial.

Mueller (2000) afirma que a "confiabilidade" é a principal característica para a atribuição do caráter científico a um periódico. Para obter confiabilidade, além da utilização de uma rigorosa metodologia científica para a geração do 
Desenvolvimento de revistas científicas em mídia digital - o caso da Revista Produção Online

conhecimento, é importante que os resultados obtidos pelas pesquisas de um cientista sejam submetidos ao julgamento de outros cientistas, seus pares. A autora ressalta ainda que, quando avaliado por um corpo de referees respeitados, o artigo científico adquire autoridade e confiabilidade. Sem a aprovação dos especialistas, o pesquisador não adquire o reconhecimento científico.

Todo o processo de produção científica, que consiste na recepção, julgamento, notificação aos autores e publicação, é feito por meio eletrônico, agilizando enormemente o intervalo de tempo entre submissão, aceitação e publicação.

Quando submetidos à avaliação, os artigos são analisados pelos editores do periódico, que, após fazerem uma préseleção, determinarão quais os parecistas poderão avaliar os trabalhos. A pré-seleção consiste em fazer uma triagem observando a relevância do artigo para a revista. Cabe aos editores administrar todo o processo de avaliação dos artigos, sempre assessorados pelo corpo avaliativo. Após a pré-seleção, o artigo é submetido a pelo menos três colaboradores do corpo editorial, de acordo com a disponibilidade de referees na área de conhecimento, determinando-se um prazo de 30 dias, reforçando-se o pedido logo após o vencimento do mesmo. A avaliação permite aceitar ou recusar o artigo imediatamente, ou ainda aceitar com a condição de que o mesmo seja modificado. Nesse último caso, os autores devem efetuar as alterações sugeridas pelo avaliador e reenviar o artigo para que seja emitido o último aceite. $O$ contato via suporte eletrônico entre editores e consultores facilita a rapidez na comunicação e na obtenção dos resultados esperados. $\mathrm{O}$ avaliador recebe o artigo em frações de segundos, confirma o recebimento do mesmo, arquiva-o em seu computador, podendo inclusive usufruir as ferramentas do Word para tecer considerações no documento original.

Considera-se essa etapa como sendo fundamental, visto que a excelência dos artigos determinará a qualidade da revista. Cabe ao referee analisar o conteúdo e a apresentação do artigo, observando a relevância do tema, a adequação do assunto em relação ao periódico, a originalidade, a riqueza das referências bibliográficas e principalmente a contribuição para a comunidade científica da área. Cabe ao corpo de referees a aprovação ou reprovação dos trabalhos. Os avaliadores emitem o parecer também via e-mail, considerando-se poucas as exceções que preferem imprimir o artigo e proferir considerações por escrito, via correio. A revista estipula as exigências que devem ser seguidas para a análise dos artigos, mediante uma ficha de avaliação, conforme detalha o quadro 2 .

Após definir a pontuação para cada item da análise, o avaliador deverá tecer considerações a respeito das modificações necessárias, ou argumentar o porquê da recusa do artigo, se for o caso.

\section{Contato com os autores}

A quarta etapa, antecedente à publicação, refere-se ao contato com os autores. Assim que recebidas, as fichas de avaliação são armazenadas no computador, sendo enviado o parecer ao autor somente quando se tiver uma posição de ambas as partes dos avaliadores.

No caso dos avaliadores que preferem enviar os artigos impressos, juntamente com as observações, encontram-se dificuldades na agilização do processo, visto que despendese de tempo para enviar o artigo ao autor via correio.

Quando um artigo é reprovado por um dos avaliadores e aprovado por outro, elege-se um terceiro avaliador para tecer as considerações a respeito. As sugestões de modificação são repassadas para o autor, que deve fazer as alterações em um prazo de 15 dias.

\section{Publicação do Artigo}

A quinta e última etapa compete à publicação do artigo propriamente dita, sendo que, para cada número da edição, são publicados no máximo cinco artigos. $\mathrm{O}$ autor é imediatamente avisado mediante o envio de um comprovante de publicação. 


\section{Cláudia Regina Ziliotto Bomfá / João Ernesto E. Castro}

Equipe de trabalho

A Revista Produção Online constitui-se de um editor, um editor Web, um conselho consultivo e um Web master, conforme demonstrado na figura 2.

O editor é o profissional responsável pela representação social do periódico científico, sendo que compete a ele divulgar o mesmo sempre que possível. É de sua alçada supervisionar todo o processo de produção científica, a receptividade dentre os autores e a demanda de novos artigos. Compete ao editor, também, selecionar novos integrantes para o conselho consultivo.

O conselho consultivo atua como referee, emitindo parecer conclusivo sobre os originais submetidos à avaliação, além de divulgar a revista em seu contexto de atuação, contribuindo para o estímulo da produção de originais. $\mathrm{O}$ editor Web tem papel fundamental no processo, justamente por se tratar de um profissional específico da mídia digital. Cabe ao mesmo o gerenciamento de todo o processo de produção científica, dentre outras tarefas:

- receber e catalogar os artigos, registrando todas as informações em um banco de dados;

- encaminhar os artigos ao editor principal;

- encaminhar os artigos aos avaliadores, juntamente com as normas de publicação e a ficha de avaliação;

- manter contato com os avaliadores, determinando os prazos para a emissão do parecer;

- manter contato com os autores, colocando-os a par da situação do artigo;

- coordenar as listas de discussão entre avaliadores e autores;

- responder às dúvidas dos autores e avaliadores;

- receber o parecer dos avaliadores em relação ao artigo, reenviando-o ao autor para que se façam as devidas alterações;

- ao receber o artigo reformulado, enviá-lo novamente aos avaliadores para que dêem o parecer final para a publicação;

- abrir uma nova edição e publicar os artigos.

Salienta-se que todo o trabalho é realizado em conjunto, sendo que todos os colaboradores participam ativamente das atividades de produção científica, cada qual com sua responsabilidade.

\section{RESULTADOS OBTIDOS}

A experiência com o gerenciamento do processo de produção científica da Revista Produção On-line possibilitou tecer recomendações práticas para a concepção de revistas
FIGURA 2

Atribuições da equipe editorial de uma revista eletrônica, em relação a uma revista impressa

\begin{tabular}{|c|c|c|c|}
\hline \multicolumn{4}{|c|}{ Equipe Editorial } \\
\hline Membros & Online & Impressa & Atribuições \\
\hline Editor & $\mathbf{x}$ & $\mathbf{x}$ & \multirow{3}{*}{$\begin{array}{l}\text { Triagem dos artigos e escolha } \\
\text { dos referees } \\
\text { Gerenciamento do processo } \\
\text { de produção científica }\end{array}$} \\
\hline Editor Web & $\mathbf{x}$ & $\theta$ & \\
\hline Conselho Editorial & $\mathbf{x}$ & $\mathbf{x}$ & \\
\hline Web Master & $x$ & $\theta$ & $\begin{array}{l}\text { Desenvolvimento e atualização } \\
\text { do site }\end{array}$ \\
\hline
\end{tabular}

Fonte: Bomfá, 2003

\section{FIGURAS 3 E 4}

Correlação de características que privilegiam as revistas eletrônicas em contraposição às impressas

\begin{tabular}{|c|c|c|}
\hline \multicolumn{3}{|c|}{ Conclusões } \\
\hline Conclusőes & Impressa & Online \\
\hline $\begin{array}{l}\text { Redução do tempo } \\
\text { de publicação }\end{array}$ & Média 2 anos & Média 4 meses \\
\hline $\begin{array}{l}\text { Disseminação da } \\
\text { pesquisa científica }\end{array}$ & Tiragem $1500 \mathrm{ex}$. & $\begin{array}{l}4.454 \text { acessos(mês } \\
\text { maio de 2004) }\end{array}$ \\
\hline Custos & $\begin{array}{l}\text { Impressắ, postagem, } \\
\text { distribuiçăo(60.000,00 } \\
\text { ano) }\end{array}$ & $\begin{array}{l}\text { Redução de custos } \\
(15.000,00 \text { ano })\end{array}$ \\
\hline $\begin{array}{l}\text { Número de artigos } \\
\text { submetidos }\end{array}$ & Menor freqüência & $\begin{array}{l}\text { Média } 5 \\
\text { submissőes/semana }\end{array}$ \\
\hline Comunicação entre & Baixxa freqüência & Interativo \\
\hline autores e leitores & & $\begin{array}{l}\text { Chat e listas de } \\
\text { discussão }\end{array}$ \\
\hline \multicolumn{3}{|c|}{ Conclusões } \\
\hline Conclusőes & Impressa & Online \\
\hline $\begin{array}{l}\text { Abrangência do } \\
\text { periódico }\end{array}$ & $\begin{array}{l}\text { Maior parte } \\
\text { Regional }\end{array}$ & Nacional \\
\hline $\begin{array}{l}\text { Apresentação do } \\
\text { conteúdo }\end{array}$ & Rígida e estática & $\begin{array}{l}\text { Versatilidade e } \\
\text { movimento }\end{array}$ \\
\hline $\begin{array}{l}\text { Recuperação } \\
\text { da informação }\end{array}$ & $\begin{array}{l}\text { Falta de } \\
\text { ferramentas }\end{array}$ & $\begin{array}{l}\text { Ferramentas de } \\
\text { busca }\end{array}$ \\
\hline $\begin{array}{l}\text { Gerenciamento da } \\
\text { produçäo } \\
\text { científica }\end{array}$ & $\begin{array}{l}\text { Dificultado } \\
\text { pelo suporte } \\
\text { fixo }\end{array}$ & $\begin{array}{l}\text { Facilitado pelas } \\
\text { vantagens dos } \\
\text { recursos em suporte } \\
\text { digital }\end{array}$ \\
\hline
\end{tabular}

Fonte: Bomfá, 2003

eletrônicas. Entende-se que o principal diferencial das revistas eletrônicas, em relação às impressas, é a interatividade com o autor. Para tanto, todas as recomendações baseiam-se no propósito de contribuir para que a edição on-line supere a versão impressa, trazendo a tona informações e dados ausentes. Destacamse, nas figuras 3 e 4, as vantagens da revista eletrônica em relação à revista impressa. 
Considera-se relevante a receptividade da comunidade científica da área de engenharia de produção, no que se refere à submissão de artigos, bem como downloads, em função das facilidades proporcionadas pelo formato digital. A revista tem tido excelente receptividade pelos leitores da área. No mês de maio, obtiveram-se 4.454 visitas, uma média de 144 acessos diários. Esse número foi $52 \%$ superior ao mês de maio de 2003 , quando ao total de acessos alcançou 2.990 visitas. Ocorreu aumento de $2.672 \%$ no número de downloads de artigos, passando de 493 no mês de maio do ano anterior para 13.665 no mesmo mês do ano de 2004 .

O número de acessos aos artigos da revista científica eletrônica de engenharia de produção tem crescido consideravelmente, em seus três anos de existência, conforme pode ser verificado na figura 5 .

FIGURA 5

Número de acessos ao site da www.producaoonline.inf.br

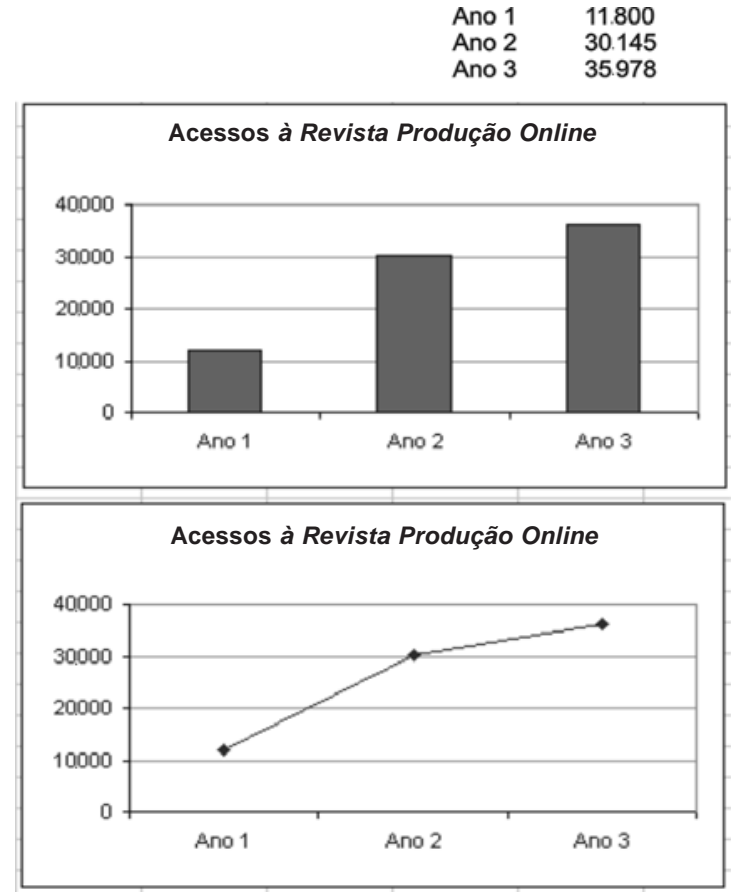

A receptividade também contempla o interesse pelos artigos publicados, conforme pode ser verificado na figura 6 .

É importante enfatizar que foram encontradas algumas dificuldades em relação à revista eletrônica, conforme destaca-se a seguir, com o intuito de buscar o aperfeiçoamento deste veículo de comunicação científica:

- em se tratando de um suporte on-line, estima-se que os referees sejam breves no parecer dos artigos, no entanto nem sempre se obtém sucesso, recorrendo-se à substituição de alguns avaliadores;
FIGURA 6

Número de downloads de artigos da revista Produção On-line

\begin{tabular}{lrrr}
\hline & Ano 1 & Ano 2 & Ano 3 \\
\hline Outubro & 100 & 250 & 440 \\
Novembro & 90 & 220 & 238 \\
Dezembro & 80 & 200 & 387 \\
Janeiro & 90 & 170 & 274 \\
Fevereiro & 100 & 140 & 2.805 \\
Março & 110 & 148 & 3.500 \\
Abril & 120 & 419 & 4.500 \\
Maio & 130 & 493 & 13.369 \\
Junho & 150 & 940 & 12.525 \\
Julho & 170 & 509 & 7.406 \\
Agosto & 120 & 560 & 12.500 \\
Setembro & 150 & 654 & 11.000 \\
\hline Total & 1.410 & 4.703 & 68.944 \\
\hline
\end{tabular}

Ano $1 \quad 1.410$

Ano $2 \quad 4.703$

Ano $3 \quad 68.944$
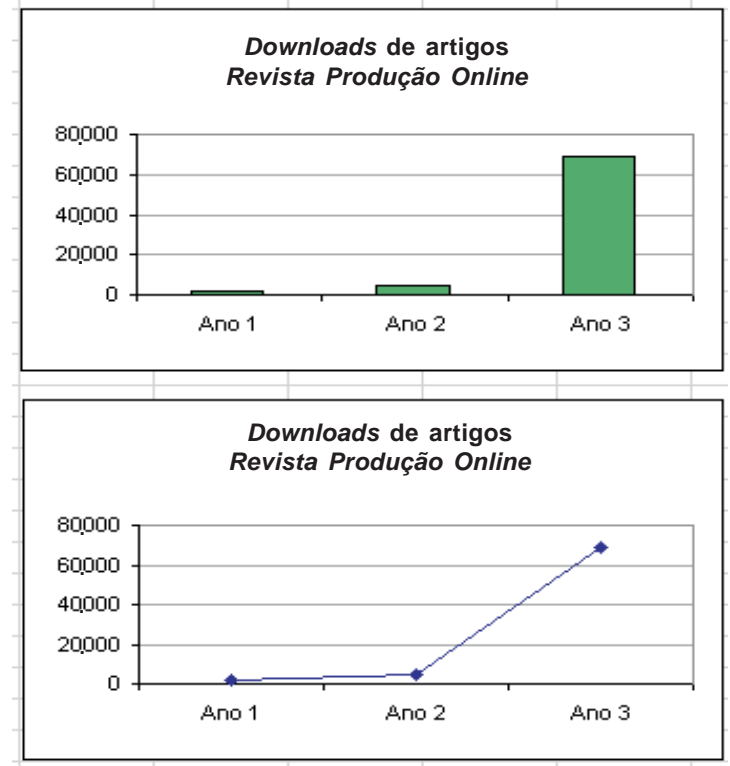

- podem ocorrer riscos de perda de informações, para tanto aconselha-se a utilização de um banco de dados, com atualizações periódicas;

- muitos autores ainda preferem os periódicos em suporte impresso, visto que se considera a cultura de aceitação das novas mídias é algo gradativo;

- o suporte digital exige maior agilidade nas respostas por parte do gerenciamento da revista.

\section{Recomendações para a elaboração de revistas}

a. Traçar um projeto determinando primeiramente o leiaute da revista, levando-se em consideração o públicoalvo, os possíveis interesses de acordo com a área temática do periódico. Um site bem estruturado e que possibilita a fácil navegação e rápido acesso às informações é fator 


\section{Cláudia Regina Ziliotto Bomfá / João Ernesto E. Castro}

fundamental para o bom andamento e boa aceitação do periódico.

b. Registrar o periódico no ISSN.

c. Definir a equipe de pessoas envolvidas no processo de gerenciamento da produção científica, determinando as respectivas funções.

d. Definir os integrantes do corpo de referees, observando as áreas de atuação, procedência, instituição e estado de origem, de modo a prezar pela qualidade das avaliações e ir ao encontro das exigências dos bancos de dados internacional, que priorizam que se determine um integrante de cada instituição/região.

e. Estabelecer critérios plausíveis para a avaliação dos artigos, determinando que sejam levados em conta os aspectos: originalidade, caráter científico, atualidade e relevância do tema, coerência e coesão textuais, contribuição para a área afim, dentre outros critérios. Além disso, é importante estabelecer prazos para a avaliação dos artigos.

f. Manter rigorosamente a periodicidade, com o intuito de submeter o periódico às bases de dados internacionais.

g. Estar em comunicação constante com o corpo editorial da revista, informando datas relevantes para a avaliação dos artigos, prazo para a publicação do próximo número do periódico, entre outros.

h. Comunicar-se com freqüência com os autores, informando a situação atual do artigo: se está sendo avaliado, se há alterações a serem efetuadas, com o intuito de atribuir credibilidade à revista científica.

i. Manter um link, em todas as páginas, possibilitando que o leitor tenha acesso às edições e artigos anteriores do periódico.

j. Divulgar o periódico nos principais sites de busca, nas instituições de ensino relacionadas ao mesmo e em bons canais de divulgação.

\section{CONSIDERAC̣ÕES FINAIS}

O empenho da equipe editorial da Revista Produção Online visa a melhorar a qualidade das produções científicas da área, buscando manter um compromisso com a publicação dos trabalhos.

Todo o processo de produção científica é acompanhado de perto por uma equipe de profissionais, comprometida com a qualidade da Revista Produção Online.
Mediante esta experiência, pode-se afirmar que as revistas científicas eletrônicas possuem grandes vantagens sobre as revistas tradicionais impressas, visto que naquelas encontra-se a facilidade de comunicação entre o corpo de avaliadores e ainda entre os autores, tudo isto via e-mail, agilizando o processo de publicação dos artigos.

Acredita-se que a tentativa de desenvolver uma revista científica em mídia eletrônica beneficiou imensamente toda a comunidade científica da área, contribuindo assim para o crescimento e para a qualidades das produções científicas.

Artigo recebido em 16-07-2004 e aceito para publicação de 18 a $21 / 10 / 2004$.

\section{REFERENCIAS}

AGUIAR, Sônia. Desatando os nós da rede. Rio de Janeiro: Senac, 1997.

BOMFÁ, Cláudia R. Z. Publicação de revistas científicas em mídia dcgital: critérios e procedimentos. Florianópolis : Visual Books, 2003.

BUTTER, D. Nature, v. 397, p. 195-200, 1999.

GARCIA, Joana C. Ribeiro; TARGINO, Maria das Graças. Ciência brasileira na base de dados do Institute for Scientific Information. Ciência da Informação, Brasília, v. 29, n. 1, p. 103-117 jan./abr. 2000. Disponível em: 〈www.ibict.br/cion-line/290100/29010011.pdf > Acesso em: dez. 2001.

LEVACOV, M. Os nvos paradigmas do texto eletrônico. In: CAMPOS, R. J. Mídia e comunicação. Rio de Janeiro : Diadorim, 1997.

MANTA, A. Guia do jornalismo na Internet. 1997. Trabalho de Conclusão de Curso. (Comunicação) - Faculdade de Comunicação da Universidade Federal da Bahia, Salvador, 1997.

UNIVERSIDADE FEDERAL DA BAHIA. Disponivel em:<http:// www.facom.ufba.br/pesq/cyber/manta/Guia/index.html>. Acesso em: 21 ago. 1997.

MCADAMS, M. Driving a newspaper on the data highway. Disponível em: <http://www.well.com/user/mmcadams/on-line.newspapers. $h t m>$.

MÜLlER, Suzana P. M. O periódico científico. In: CAMPELLO et al. Fontes de informação para pesquisadores e profissionais. Belo Horizonte : Editora da UFMG, 2000. p. 72-95.

Passado e futuro das revistas científicas. Ciência da Informação, Brasília, v.25, n.3, p.383-386, set./dez. 1996. Disponivel em: 〈www.ibict.br/cion-line/250396/25039614.pdf >. Acesso em: out. 2002 .

PESSANHA, Charles. Critérios editoriais de avaliação científica: notas para discussão. Ciência da Informação, Brasilia, v. 27, n. 2, p. 236-238, 1998. Disponível em: 〈http://.../SciELO.php?script=sci 〉. Acesso em: nov. 2001.

STUMPF, Ida Regina C. Passado e futuro das revistas científicas. Ciência da Informação, Brasília, v. 25, n. 3, p. 383-386, set./dez. 1996. Disponível em: <www.ibict.br/cion-line/250396/25039614.pdf >. Acesso em: out. 2002. 